\title{
REPRESENTAÇÕES SOCIAIS DOS DISCENTES SOBRE CURSOS SUPERIORES SEQÜENCIAIS
}

\section{1- Maria Gentila Vieira Guedes \\ Faculdade Boa Viagem - FBV \\ mariagentila@gmail.com}

\author{
3- Giselle Cesar Vieira Diniz \\ Faculdade Boa Viagem - FBV \\ giselle34@gmail.com
}

\begin{abstract}
2- Fátima Regina Ney Matos
Universidade Estadual do Ceará - UECE

fneymatos@globo.com
\end{abstract}

\author{
4- Lauro Cesar Vieira Filho \\ Faculdade Boa Viagem - FBV \\ lauro@fbv.br
}

Diego Maganhotto Coraiola - Editor

\section{RESUMO}

O presente trabalho tem como proposta verificar se os discentes dos cursos seqüenciais de uma Instituição de Ensino Superior particular, localizada em Recife, resignificam suas representações sociais no decorrer do curso. Esse trabalho é importante para o meio acadêmico porque se espera contribuir positivamente para esclarecer dúvidas a respeito dessa modalidade de ensino superior, favorecer a reflexão sobre esses cursos e compreender as representações sociais que os discentes possuem dos cursos superiores seqüenciais. Com a vivência na coordenação junto aos alunos podese observar o envolvimento de alguns em dar continuidade à vida acadêmica. Para construir o referencial teórico, foi mostrado um breve histórico da implantação dos cursos seqüenciais e da contextualização de representações sociais. Com o objetivo de analisar as representações sociais dos discentes sobre a formação nos cursos seqüenciais, é que se considera mais adequada a abordagem qualitativa. Como método de coleta, foi utilizado o teste de evocação de palavras. Pode-se concluir que está havendo uma re-significação das representações sociais dos discentes e que o pragmatismo inicial vem sendo modificado no decorrer do curso por um interesse mais acadêmico.

\section{Palavras-Chave}

Representações sociais, Cursos superiores seqüenciais, Ensino superior.

\section{ABSTRACT}

The present article has as proposal to verify if the learning of the sequential courses of an Private Institution of Superior Education, located in Recife, reverse speedmean its social representations in elapsing of the course. This article is important for the half academic because it expects to contribute positively to clarify doubts regarding this modality of superior education, to favor the reflection on these courses and to understand the social representations that the learning possess of the sequential superior courses. With the experience in the coordination next to the pupils the involvement of some in giving continuity can be observed to the academic life. To construct the theoretical referential, a historical briefing of the implantation of the sequential courses and the social representations was shown. With the objective to analyze the social representations of the learning on the formation in the sequential courses, it is that the qualitative boarding is considered more adequate. As collection method, the test of mandate of words was used. It can be concluded that it is having a re-signification of the social representations of the learning and that the initial pragmatism comes more being modified in elapsing of the course for an interest academic.

Keywords

Social representations, Sequential superior courses, Superior education. 


\section{Introdução}

Em 1996 a Lei de Diretrizes e Base da Educação - LDB permitiu a criação de um novo tipo de ensino superior, os cursos seqüenciais, modalidade que exige um menor tempo de integralização Desde então, o Brasil passou a conviver com quatro modalidades de ensino superior: cursos seqüenciais, de graduação, de pós-graduação e de extensão.

Pode-se considerar que a formação de nível superior é, atualmente, um pré-requisito básico para estar empregado. Sabendo que o indivíduo vive a maior parte do seu tempo dentro de uma organização, na qual o bom desempenho e a excelência na prestação de serviços estão sendo cada vez mais exigidos, não se pode prescindir de uma prática profissional dissociada de uma teoria que a fundamente.

Ao se pesquisar sobre cursos superiores de menor duração, observa-se que a literatura existente ainda é insuficiente para dar conta dos inúmeros desafios que se apresentam na prática. $\mathrm{O}$ preconceito acerca dos cursos seqüenciais resultou na pouca produção sobre o tema, marcada por críticas da comunidade acadêmica que generaliza os cursos como "aligeirados". Em contrapartida, pode ser observado um crescimento acelerado dessa modalidade de ensino no Brasil. Com essa pesquisa pretende-se discutir sobre os cursos seqüenciais visando compreender seu universo, que já é uma realidade em um grande número de instituições no Brasil. Esse trabalho é importante para o meio acadêmico porque se espera contribuir para esclarecer dúvidas a respeito dessa modalidade de ensino superior, favorecer a reflexão sobre esses cursos e compreender as representações sociais que os discentes possuem dos cursos superiores seqüenciais.

Através da prática na coordenação de cursos seqüenciais foi possível realizar várias observações e, assim, levantar algumas questões sobre o tema. Inicialmente, os discentes têm uma representação social aplicada e prática em relação à formação nos cursos superiores de menor duração. $O$ interesse do ingressante está voltado para a obtenção do diploma, cursos mais rápidos e, consequentemente, mais econômicos, aquisição de conhecimentos teóricos para aplicar na sua prática de forma imediata. Considera-se a possibilidade de que ao longo da formação, os alunos construam representações sociais superando a relação apenas pragmática, tecnicista e por vezes superficial, em busca de uma relação com o saber. Acredita-se que a convivência com o mundo acadêmico promova uma mudança de representação sobre esses cursos por parte dos discentes.

Assim, o objetivo deste estudo foi verificar se os discentes dos cursos seqüenciais de uma Instituição de Ensino Superior particular, localizada em Recife, re-significam suas representações sociais no decorrer do curso, tendo em vista que, com a vivência junto aos alunos foi observado o interesse de alguns em dar continuidade à vida acadêmica, de tal forma que, a partir dos trabalhos apresentados em sala de aula, surgiram artigos publicados e apresentações orais em congressos, continuação dos estudos na graduação tradicional ou até mesmo em cursos de pós-graduação lato sensu, o que constitui uma nova representação sobre sua vida acadêmica.

O artigo apresenta a seguir a revisão da literatura, que aborda a profissionalização do ensino no Brasil e as representações sociais e os procedimentos metodológicos, onde são apresentados 0 delineamento da pesquisa, 0 universo e os instrumentos de coleta. A seguir, são discutidos os resultados obtidos e, por fim, são tecidas as considerações finais.

\section{Profissionalizando o Ensino}

Até o início do século XIX, não havia no Brasil faculdades ou universidades e a elite brasileira obtinha seu grau superior em universidades européias, tanto que Anísio Teixeira considerava a Universidade de Coimbra como a "nossa primeira universidade", pois ali se graduaram, nos três primeiros séculos da história brasileira, mais de 2.500 jovens aqui nascidos (TEIXEIRA, 1989).

Somente a partir da chegada do príncipe regente D. João VI, em 1808, a política educacional adotada pelo governo português para o Brasilcolônia foi modificada e diversas instituições educativas e culturais foram inauguradas. Em relação ao ensino superior, inicialmente foi criado em Salvador o Curso de Cirurgia, Anatomia e Obstetrícia (OLIVEN, 2005) e, com a transferência da corte para o Rio de Janeiro, foram fundadas nessa cidade as Escolas Régias Superiores de Medicina e Cirurgia e de Engenharia além da Escola de Belas Artes e das Academias Militares (MASETTO, 2006).

Da formação em universidades européias às primeiras faculdades, o ensino superior brasileiro sempre se caracterizou por ser elitista. Com a criação da primeira universidade, Universidade do Rio de Janeiro, em 1920, o cenário não se modificou e conservou a compartimentalização de 
faculdades, a estrutura de poder apoiada na cátedra e o caráter elitista do ensino [...] (FÁVERO, 1980).

A tarefa de pensar e de obter uma boa educação cabia aos escalões mais altos, tais como a gerência e a direção. Com isso, o acesso às universidades ficava restrito as classes dominantes, economicamente favorecidas; enquanto ao ensino profissional cabia oferecer uma formação para as classes economicamente desfavorecidas, como os filhos dos operários, que necessitavam de treinamento das técnicas para ocupar postos de trabalho bem definidos, que visavam tão somente o fazer, sem necessidade de pensar ou questionar o modo de produção (MANFREDI, 2002, p. 55).

Ou seja, a sociedade brasileira organizou-se através de polarizações hierárquicas, predominando a postura de cima para baixo (DEMO, 1996) mantendo uma situação de equilíbrio, onde uma minoria sempre teve acesso à educação e uma maioria permanecia à margem do ensino superior.

País de industrialização tardia, apenas em 1928 a renda industrial no Brasil superou pela primeira vez a renda agrária (COTRIM, 1995), nunca houve uma preocupação com a formação de mão-de-obra para o mercado de trabalho. O ensino profissional no país somente se expandiu com o desenvolvimento industrial, devido à exigência por melhor qualificação para o trabalho, a criação de novas fábricas e a apropriação de tecnologia mais moderna. Com a industrialização surgiu à relação entre trabalho e educação e, com isso, a necessidade de treinamento para a realização de uma tarefa específica tornou-se cada vez mais exigida.

Com essa política educacional excludente, a grande maioria dos jovens não tinha a oportunidade de cursar uma faculdade, o que dificultava o acesso aos melhores empregos, frente a uma concorrência onde o mais competitivo é aquele que apresenta maior escolaridade. A dificuldade para conseguir mão-de-obra qualificada fez com que o governo procurasse envolver as indústrias na qualificação de seus funcionários e demais pessoas da sociedade e foram criados órgãos como o Serviço Nacional de Aprendizagem Industrial - SENAI e o Serviço Social da Indústria - SESI.

Em um esforço para modificar esse cenário de exclusão de tantos jovens sem acesso ao ensino superior e consequentemente sem competitividade, no final da década de 1960, o Ministério da Educação incentivou a abertura de Cursos Superiores de Curta Duração, que tivessem como foco o mercado de trabalho, respaldados na Lei 4.024, do ano de 1961, primeira LDB e legislações subseqüentes. O objetivo desses cursos foi formar mais rapidamente os indivíduos em um campo específico do saber, e com isso, permitir a sua ocupação em postos fixos nas indústrias. Neste sentido, surgiram alguns cursos com currículos compactados, como por exemplo, o de engenharia operária que sofreu um preconceito enorme por parte dos egressos dos cursos de engenharia tradicionais e do próprio mercado de trabalho.

Com o Decreto Lei 547, de 1969 , os primeiros cursos profissionais de curta duração foram concretizados. Segundo o parecer $n^{\circ} .436$ de 02/04/2001, os primeiros cursos superiores de tecnologia surgiram em instituições públicas e privadas na cidade de São Paulo. A proposta desses cursos era voltada para uma educação profissional, uma formação específica, focada nas demandas do mercado de trabalho, com menor tempo de duração (entre dois a três anos), com currículos bem definidos e práticos. Ao contrário dos cursos de engenharia operária, os cursos superiores de tecnologia foram aceitos pela sociedade e pelo mercado e ao longo desses anos passaram por mudanças que melhor os adaptaram aos dias atuais.

Inspirado no modelo norte-americano dos community colleges, que se caracterizavam por uma orientação mais prática e voltada para atender a necessidade do mercado de trabalho local (OLIVEN, 2005), o então senador Darcy Ribeiro (PDT/RJ), em 1996, criou e introduziu na Educação Superior Brasileira os cursos seqüenciais. A LDB 9394/96, especificou no art. 44 a instituição de dois tipos de cursos seqüenciais: formação específica e complementação de estudo, proporcionando uma inovação no horizonte da educação superior (PEREIRA, 2007).

Os cursos de formação específica possuem somente destinação coletiva, carga horária préestabelecida de no mínimo 1600 h/a, duração de 400 dias letivos e projeto pedagógico específico, conferindo ao término do curso diploma expedido pela instituição de ensino e reconhecimento pelo órgão competente. Já os cursos de complementação de estudos podem ser individuais ou de forma coletiva, o próprio aluno escolhe a disciplina ou conjunto de disciplinas que deseja cursar até obter um mínimo exigido de 180 h/a para expedição de um certificado, conforme resolução CES n. 1 de 27 de janeiro de 1999, artigos $3^{\circ}, 4^{\circ} \mathrm{e}$ $5^{\circ}$. Os cursos seqüenciais de formação específica e os cursos de graduação tecnológica apresentam muitas semelhanças entre si, são organizados em um campo do saber, possuem um viés profissionalizante, têm menor tempo de duração. Não obstante, existem alguns fatores que os diferenciam. O mais importante deles é que os tecnológicos conferem diploma de graduação e os 
seqüenciais de formação específica diploma de nível superior.

Em 1990 houve uma enorme expansão do ensino superior privado no Brasil, superando as universidades públicas em quantidade de discentes. A criação dos cursos superiores de curta duração ampliou ainda mais a procura pelas universidades e faculdades privadas. De acordo com dados do Ministério da Educação (BRASIL, 2008a) entre os anos 2002 e 2003, o número dos cursos aumentou 23\%, passando de 550 para 677 , e o total de concluintes cresceu $125 \%$, chegando a 19,9 mil. Com essa expansão, a preocupação com a qualidade do ensino se acentuou e as críticas surgiram apontando essa modalidade de ensino como promotora de uma quebra no modelo único de universidade, marcado pela indissociabilidade do ensino, pesquisa e extensão. Desta forma, teria sido promovido o que se considerou uma massificação do ensino superior em nosso país.

Entretanto autores como Martins (2004), discordam dessa perspectiva de análise, argumentando que esses cursos têm uma proposta de ensino diferente, frisando que o modelo anterior forçava vocações diferentes a se encaixar numa formula única. Este novo modelo leva em conta que nem todas as formações têm vocação para o bacharelado. Ele também explica que é preciso ter muito claro que os seqüenciais não foram concebidos para ser compactos dos cursos de graduação, algo do tipo 'faça quatro anos em dois' (MARTINS, 2004). É uma opção diferenciada. Essa diferença fica clara principalmente no perfil do aluno do curso seqüencial que, na grande maioria está na faixa dos 29 anos, já tem experiência profissional e está inserido no mercado, segundo pesquisa da Associação Nacional de Educação Tecnológica (ANET). Inicialmente esse aluno vem em busca apenas de complementar a sua formação educacional, mas no decorrer do curso, é possível que ocorra uma mudança na representação social que o mesmo tem de um curso seqüencial, o que motivou a realização dessa pesquisa.

\section{Sobre as Representações Sociais}

O conceito de representações sociais, de acordo com Minayo (1995) e Cavendon (2003), tem sua origem na obra As formas elementares da vida religiosa, na qual Durkheim (1978) afirma que os primeiros sistemas de representações que o homem fez do mundo e de si mesmo são de origem religiosa e as representações religiosas são representações coletivas, tendo em vista que exprimem realidades coletivas (DURKHEIM, 1978).
De acordo com o autor, a sociedade é a mais alta manifestação da natureza e, assim sendo, as representações coletivas sempre acrescentam alguma coisa às representações individuais. Durkheim (1978) também diferencia representação impessoal - o conceito é uma representação essencialmente impessoal - de representação sensível.

As representações sensíveis estão em perpétuo fluxo; impelem-se umas às outras como as ondas de um rio e, mesmo durante o tempo que elas duram, não permanecem semelhantes a si mesmas. Cada uma delas é função do instante preciso em que surgiu. Não estamos jamais seguros de reencontrar uma percepção tal como a provamos na primeira vez; pois, se a coisa percebida não mudou, nós não somos mais os mesmos homens (DURKHEIM, 1978, p. 235).

As representações sociais podem ser vistas como um híbrido entre os conceitos de representações coletivas e de representações sensíveis, tendo em vista que não são nem tão inflexíveis como as primeiras e nem tão mutáveis, como as segundas. Provavelmente é nesse sentido que Spink (1995) considera a representação social tanto produto quanto processo. Como pensamento constituído ou campo estruturado que visa compreender os elementos que constituem as informações, imagens, opiniões, crenças, as representações sociais são produto. Enquanto processo, surgem como idéias formadoras voltadas para a compreensão da elaboração e transformação na influência mútua social.

De acordo com Cavedon (2003, p. 101-102), "a noção de 'representação social' encontra-se em um limbo entre a Antropologia, a Sociologia e a Psicologia Social [...], pois em cada um desses domínios existe ora a supremacia do social sobre o individual, ora o individual é visto se sobressaindo ao social", o que vem gerando uma polissemia conceitual.

Serge Moscovici é considerado o maior representante da vertente européia da teoria (CAVEDON, 2003), partindo de seus estudos a consolidação da expressão "representações sociais". Moscovici (1995) considera que a representação social tem um papel importante no conflito entre o individual e o social, procurando um equilíbrio e uma complementaridade entre essas categorias.

[...] todas as culturas que conhecemos possuem instituições e normas formais que conduzem, de uma parte, à individuação, e de outra à socialização. As representações que elas elaboram carregam a marca desta tensão conferindo-lhe um sentido e procurando mantê-la nos limites do suportável. Não existe sujeito sem sistema nem sistema sem sujeito. O papel das representações partilhadas é o de assegurar que sua coexistência é possível (MOSCOVICI, 1995, p. 12). 
Os papéis exercidos pelo pensamento social podem ser analisados conforme três vertentes: sociológica, psicológica e psicossociológica (MOSCOVICl, 2003), sendo que a concepção psicossociológica integra as vertentes psicológica e sociológica e fundamenta a Teoria das Representações Sociais (MOSCOVICI, 2003).

De acordo com a vertente sociológica, a classe social impõe uma ideologia sobre indivíduos e grupos. $\mathrm{Na}$ vertente psicológica, os indivíduos processam e transformam as informações recebidas. Por fim, na vertente psicossociológica, os indivíduos participam da construção da sociedade através das interações sociais e não apenas processam informações ou introjetam ideologias; ou no dizer de Jovchelovitch (1995, p. 78), "o sujeito não está subtraído da realidade social, nem meramente condenado a reproduzi-la. Sua tarefa é elaborar a permanente tensão entre um mundo que já se encontra constituído e seus próprios esforços para ser um sujeito".

Spink (1995) considera que as representações sociais são estruturas estruturantes que mostram a capacidade de criação e de transformação da realidade social e que precisam ser compreendidas dentro de um contexto inter-relacional. Assim sendo, nesse trabalho procurou-se identificar mudanças nas representações sociais de alunos matriculados em cursos seqüenciais, tendo em vista que a realidade construída pelos atores sociais é passível de mudanças a partir de novos relacionamentos e de novos contextos, apresentando núcleos positivos de transformação (MINAYO, 1995).

\section{Procedimentos Metodológicos}

Para obter uma metodologia adequada a essa pesquisa, foi necessário um período inicial de observações e pesquisas bibliográficas para compreender melhor o tema proposto.

Falar de ciência esta cada vez mais difícil, pois novos paradigmas têm sido gerados pela própria ciência, questionando pressupostos e procedimentos obtidos anteriormente. Hoje, a maioria dos cientistas admite que o conhecimento nunca é inteiramente objetivo, que os valores dos cientistas podem interferir no seu trabalho, que os conhecimentos gerados pela ciência não são infalíveis e que mesmo os critérios para distinguir o que é e o que não é ciência variam ao longo da história (ALVES-MAZZOTTI; GEWANDSZNAJDER, 2001, p. 109)

A história nos mostra a hegemonia da ciência sobre outras formas de conhecimento. Minayo (2002, p. 10) cita duas razões: a primeira de ordem externa a ela mesma está na sua possibilidade de responder a questão técnica e tecnológica postas pelo desenvolvimento industrial. A segunda razão, de ordem interna, consiste no fato dos cientistas terem conseguido estabelecer uma linguagem fundamentada em conceitos, métodos e técnicas para a compreensão do mundo, das coisas, dos fenômenos, dos processos e das relações.

Com o objetivo de analisar as representações sociais dos discentes acerca da formação dos cursos seqüenciais, é que se considera mais adequada à utilização da pesquisa qualitativa, uma vez que esta "trabalha com o universo de significados, motivos, aspirações, crenças, valores e atitudes, o que corresponde a um espaço mais profundo das relações, dos processos e dos fenômenos que não podem ser reduzidos à operacionalização de variáveis" (MINAYO, 2002, p. 22).

Entendendo o processo de investigação como um ato de criação e de conhecimento sobre a realidade social é que fez-se uso também de dados quantitativos, a fim de oferecer um panorama das representações sociais dos discentes sobre os cursos seqüenciais.

É importante citar que existem muitos conflitos sobre esses tipos de pesquisa qualitativa e quantitativa. Correntes teóricas falam que não existe um continuum entre elas. A qualitativa seria o subjetivo, mostraria a qualidade, a compreensão e 0 significado. A quantitativa representaria 0 espaço científico, o objetivismo, a quantidade, a explicação. Entretanto, Santos Filho e Gamboa (1995, p. 104) relatam que "a superação do falso dualismo é possível quando resgatamos os conceitos de totalidade e de processo, ou seja, superamos a separação sujeito-objeto, quando situamos os dois elementos fundamentais da relação cognitiva em um todo maior". Minayo (2002, p. 22) também afirma que "o conjunto de dados quantitativos e qualitativos não se opõem. Ao contrário, se complementam, pois a realidade abrangida por eles interage dinamicamente, excluindo qualquer dicotomia".

\subsection{População e Amostra}

A instituição de ensino pesquisada possui 1.788 alunos matriculados em cursos seqüenciais no segundo semestre de 2008 e vem apresentando uma curva ascendente de crescimento a cada semestre, conforme pode ser observado no gráfico 1. 
Gráfico 1 - Total de Alunos Matriculados em Todos os Cursos Sequenciais da IES

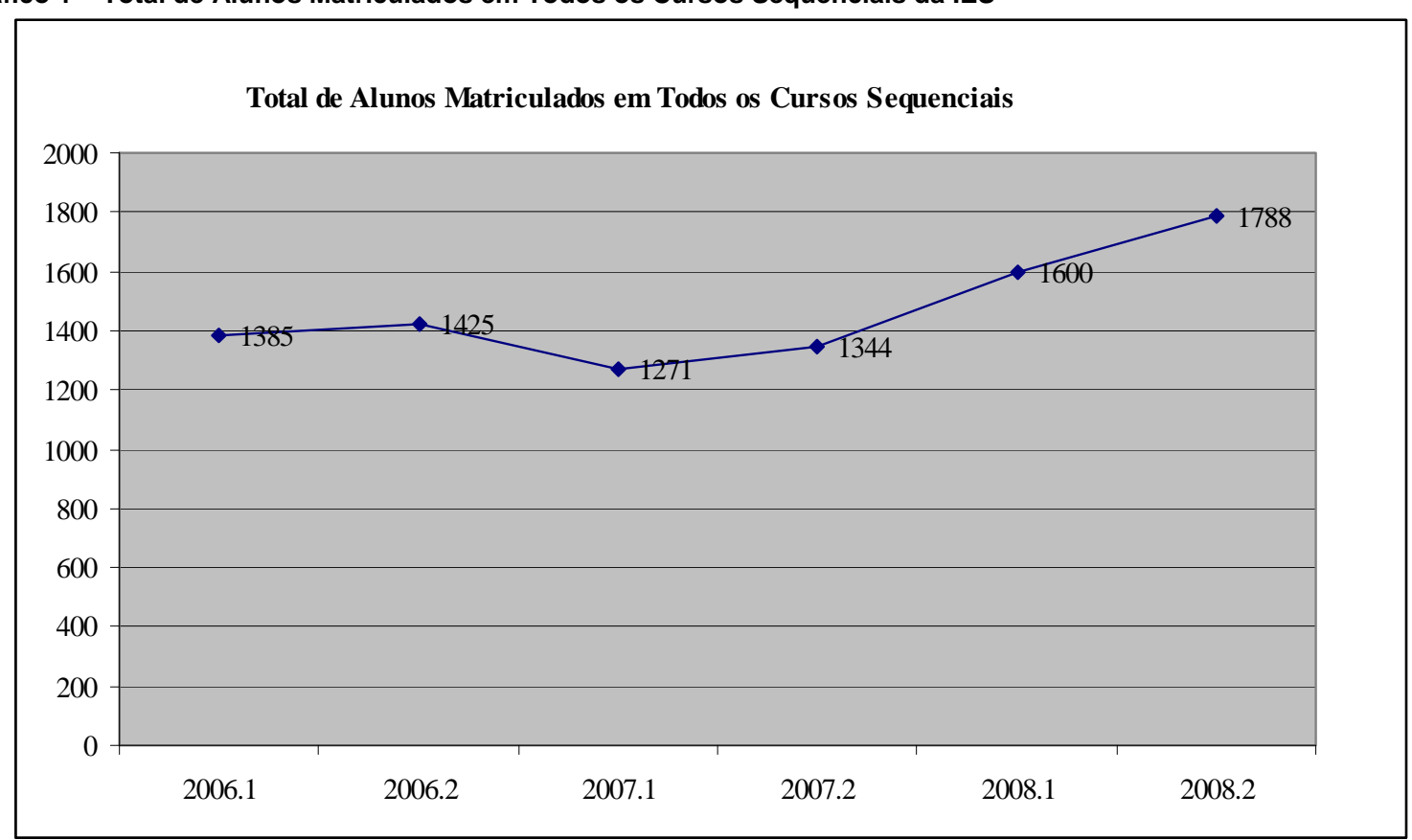

Fonte: pesquisa direta, 2008

Atualmente, a IES oferece os cursos seqüenciais de Gestão de Marketing, Gestão de Negócios, Gestão de Pessoas, Gestão Financeira, Gestão Hospitalar e Logística, os três últimos cursos sendo oferecidos a partir do segundo semestre do ano de 2007.

$\mathrm{Na}$ pesquisa em questão a amostra foi formada apenas pelos alunos matriculados nos primeiros e nos últimos semestres, ou seja, os ingressantes em agosto de 2008 e os que concluiriam o curso no final desse ano, justamente para analisar se houve re-significação de representações sociais no decorrer do curso. No quadro 1, a seguir, apresenta-se a quantidade de alunos ingressantes e concluintes dos cursos seqüenciais de Gestão de Marketing, Gestão de Negócios e Gestão de Pessoas. Os alunos dos outros cursos oferecidos não participaram da pesquisa, pois ainda não havia concluintes quando da realização do estudo. Curso

\begin{tabular}{|c|c|c|c|c|c|c|}
\hline \multirow[b]{2}{*}{ Gestão de Marketing } & \multicolumn{2}{|c|}{ Ingressante } & \multicolumn{2}{|c|}{ Concluinte } & \multicolumn{2}{|c|}{ Total } \\
\hline & 43 & $33,08 \%$ & 13 & $17,10 \%$ & 56 & $27,17 \%$ \\
\hline Gestão de Negócios & 41 & $31,54 \%$ & 19 & $25,00 \%$ & 60 & $29,16 \%$ \\
\hline Gestão de Pessoas & 27 & $20,77 \%$ & 4 & $5,27 \%$ & 31 & $15,05 \%$ \\
\hline Não Informado & 19 & $14,61 \%$ & 40 & $52,63 \%$ & 59 & $28,63 \%$ \\
\hline Total & 130 & $100 \%$ & 76 & $100 \%$ & 206 & $100 \%$ \\
\hline
\end{tabular}

Fonte: pesquisa direta, 2008

No quadro 1, pode-se observar que o número de ingressantes é superior ao de concluintes. Devese salientar que quantidade significativa de alunos, no decorrer do curso, opta por cursar menos disciplinas, principalmente com o intuito de reduzir seus custos.

\subsection{Instrumentos de Coleta}

O caminho investigativo que foi seguido nessa pesquisa deu-se a partir das observações e reflexões sobre o trabalho realizado em uma Instituição de Ensino Superior, nos cursos superiores seqüenciais. A observação, segundo 
Alves-Mazzotti e Gewandsznajder (2001, p. 164), "é extremamente valorizada pelas pesquisas qualitativas", portanto partindo de observações, foram buscadas teorias que fundamentassem 0 objetivo da pesquisa.

Como instrumento de coleta foi utilizado, além da observação direta permitida pela prática docente e de coordenação, um questionário baseado em um teste de evocação de palavras. O teste de evocação de palavras é um método de coleta de dados no qual os sujeitos da pesquisa mencionam, oralmente ou por escrito, um determinado número de palavras relacionadas a uma expressão indutora (VERGARA, 2006). Em relação a este método de coleta, Coutinho (2001, p. 323) aponta que deve haver uma questão-estímulo do tipo "Se eu lhe digo a palavra depressão, quais as seis primeiras palavras que lhe vem à mente?".

O teste de evocação de palavras, de acordo com Vergara (2006) vem sendo aplicado em estudos nos campos da saúde, administração e psicologia social, referenciados pela teoria das representações sociais, sem, no entanto, esgotarse nesta. Como o objetivo da pesquisa foi verificar se os discentes dos cursos seqüenciais de uma IES particular, localizada em Recife, re-significam suas representações sociais no decorrer do curso, fez-se imprescindível a utilização do teste.

O questionário foi formado por dois blocos, o primeiro referindo-se ao perfil do respondente e o segundo buscando sobre a representação social do curso seqüencial. As questões-estímulo apresentadas foram: Quando você pensa em pontos positivos do curso seqüencial, que palavras Ihe vêm à mente? E quanto aos pontos negativos? Em relação ao curso seqüencial, quais as primeiras palavras que lhe vem à mente? Que palavras Ihe vêm à mente quanto o que lhe motivou para cursar um seqüencial, quanto ao seu objetivo e quanto à expectativa em relação a este tipo de curso? A expressão indutora sempre foi "curso seqüencial".

Com base nas respostas obtidas, procurou-se fazer um levantamento das representações sociais dos discentes que estão no primeiro período e identificar se houve re-significação dessas representações durante o período de formação.

\section{Discussão dos Resultados}

Em relação ao gênero, observa-se um equilíbrio entre os sexos masculino e feminino, ainda que haja uma leve predominância do sexo masculino, possivelmente devido ao perfil dos cursos pesquisados, gestão de negócios, gestão de marketing e gestão de pessoas. A faixa etária do alunado concentra-se entre 24 a 36 anos, sendo que nesse intervalo encontram-se mais da metade dos alunos.

A maioria dos alunos cursou o ensino médio formal, sendo insignificante a quantidade dos que fizeram o supletivo ou o curso técnico. É interessante observar que no universo pesquisado, um terço dos alunos iniciou um curso de graduação, que não chegou a ser concluído.

Após a conclusão do segundo grau, geralmente por necessidade financeira, o aluno do curso seqüencial optou por entrar no mercado de trabalho, em detrimento da continuação dos estudos. Com a atual situação de mercado, acentua-se a concorrência e um dos diferenciais no qual a pessoa investe é a educação, que possibilitará a obtenção de um diploma. São significativas as exigências e pressão do mercado de trabalho pela obtenção do diploma, como já apontado por Oliven (2005), tanto assim que praticamente todos os alunos estão vinculados a alguma empresa. Pode-se considerar que um número significativo de alunos são pequenos empreendedores que estão buscando um embasamento para melhor administrar seu negócio.

Profissionalmente estabilizado, esse aluno vem sentindo a necessidade de complementar a sua formação educacional. Uma opção que vem se apresentando viável é o curso seqüencial. Assim sendo, inicialmente o aluno procura esse tipo de curso com uma visão prática, ou seja, é um curso realizado em menor intervalo de tempo e direcionado para as suas necessidades mais prementes, diferentemente do que é proporcionado pelo bacharelado, como já mostrado por Martins (2004).

No gráfico 2, pode-se observar a frequência das palavras evocadas pelos discentes. 
Gráfico 2 - Palavras Evocadas

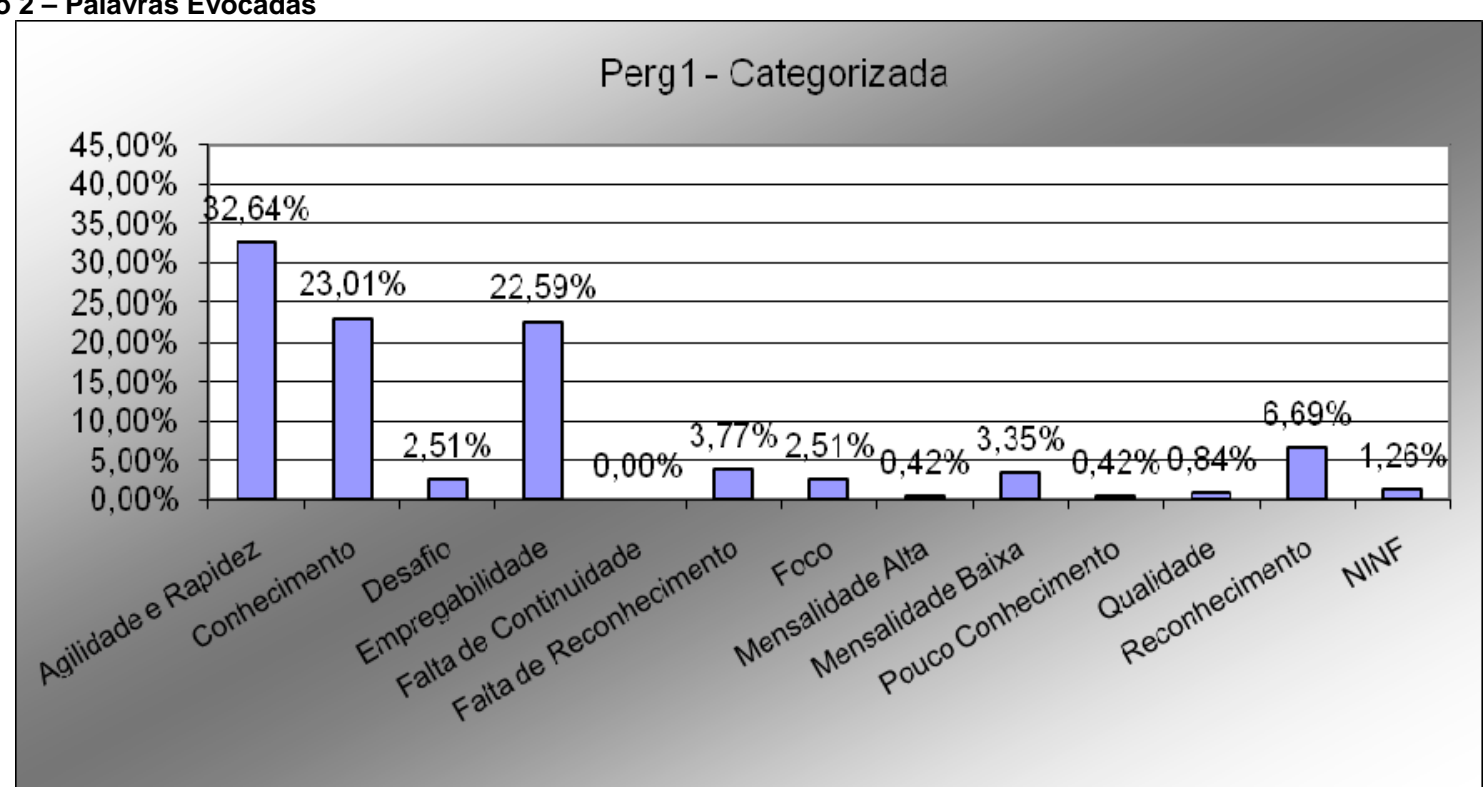

Fonte: pesquisa direta, 2008

Os principais resultados da pesquisa estão sumariados no quadro 2, apresentado a seguir.

Quadro 2 - Palavras Evocadas aos Seqüenciais

\begin{tabular}{|c|c|c|c|}
\hline Ordem Crescente de Evocação & & & \\
\hline Item & Ordem & Ingressantes & Concluintes \\
\hline \multirow[t]{3}{*}{ Pontos positivos } & 1 & Rapidez & Rapidez \\
\hline & 2 & Empregabilidade & Empregabilidade \\
\hline & 3 & $\begin{array}{l}\text { Reconhecimento } \\
\text { profissional }\end{array}$ & $\begin{array}{l}\text { Reconhecimento } \\
\text { profissional }\end{array}$ \\
\hline Pontos negativos & 1 & $\begin{array}{ll}\text { Falta } & \text { de } \\
\text { reconhecimento social }\end{array}$ & $\begin{array}{l}\text { Falta } \\
\text { reconhecimento social }\end{array}$ \\
\hline \multirow[t]{3}{*}{$\begin{array}{ccccc}\text { Palavras } & \text { evocadas } & \text { sobre } & \text { os } & \text { cursos } \\
\text { seqüenciais } & & & & \\
\end{array}$} & 1 & Rapidez & Rapidez \\
\hline & 2 & Empregabilidade & Conhecimento \\
\hline & 3 & Conhecimento & Empregabilidade \\
\hline \multirow[t]{3}{*}{ Motivação } & 1 & Rapidez & Empregabilidade \\
\hline & 2 & Empregabilidade & Conhecimento \\
\hline & 3 & Conhecimento & Rapidez \\
\hline \multirow[t]{3}{*}{ Objetivos com a realização do curso } & 1 & Rapidez & Rapidez \\
\hline & 2 & Empregabilidade & Conhecimento \\
\hline & 3 & Conhecimento & Empregabilidade \\
\hline \multirow[t]{3}{*}{ Expectativas com a realização do curso } & 1 & Empregabilidade & Conhecimento \\
\hline & 2 & Conhecimento & Empregabilidade \\
\hline & 3 & Reconhecimento & Reconhecimento \\
\hline
\end{tabular}

Fonte: Pesquisa direta, 2008

Por meio da prática docente e de coordenação, foi observado que o aluno procura um curso seqüencial com uma visão prática, ou seja, um curso rápido, econômico e que possibilita um conhecimento aplicado de forma imediata à sua realidade profissional. Os dados coletados através da evocação de palavras corroboraram o que foi observado empiricamente, pois as palavras mais citadas como ponto positivo de um curso seqüencial foram rapidez, empregabilidade e 
reconhecimento social, tanto pelos ingressantes quanto pelos concluintes. Como ponto negativo, os concluintes consideraram a falta de reconhecimento profissional, tendo em vista que algumas empresas ainda desconhecem essa modalidade de ensino.

É necessário que se conceitue a palavra empregabilidade, tendo em vista que a mesma é um neologismo que vem se consolidando no mundo dos negócios (SAVIANI, 1997). Empregabilidade, de acordo com Costa (2004, p. 322), "significa desenvolver um conjunto de habilidades, aptidões e conhecimentos compatíveis com as exigências do mercado de trabalho, de forma a consolidar um perfil profissional interessante e atraente para futuros empregadores", ou seja, empregabilidade é a habilidade de ter, manter e, potencialmente, conquistar um emprego em um mercado dinâmico e mutável.

As questões seguintes ajudam a elucidar a pergunta de partida, porque procuram identificar se ocorreu mudança em relação à imagem do curso seqüencial no decorrer da formação.

A questão inicial no questionário apresentado aos alunos, tanto ingressantes quanto concluintes, procurou evocar palavras recorrentes que thes vinham a mente quando se utiliza a expressão "cursos seqüenciais" como indutora. O ingressante evocou prioritariamente as seguintes palavras: rapidez, empregabilidade e segurança. Em relação ao concluinte, mantém-se no mesmo nível de escolha em relação à rapidez, porém há uma modificação na ordem das palavras, pois conhecimento passa a ser a palavra priorizada, em detrimento de empregabilidade. Já é possível observar, por meio da análise das palavras evocadas, que está ocorrendo uma alteração nas representações sociais do discente em relação à imagem do curso seqüencial.

Quanto ao motivo de escolha do referido curso, o ingressante prioriza a seguinte seqüencia: rapidez, empregabilidade, conhecimento. O concluinte inverte a ordenação e indica a seguinte seqüência: empregabilidade, conhecimento, rapidez. O conhecimento passa a ser priorizado em detrimento da rapidez e a empregabilidade, que atualmente está significativamente relacionada ao conhecimento, pois, de acordo com dados do Instituto Brasileiro de Geografia e Estatística - IBGE (BRASIL, 2008b), quem conclui a universidade tem salários, em média, 168\% mais elevados do que aqueles que possuem apenas o ensino médio, além de maiores chances de conseguir um emprego, também passa a ocupar uma nova posição como palavra evocada.

Ao tratar do objetivo, ou seja, o que o aluno pretende ao buscar o curso seqüencial o ingressante evoca essa ordem de palavras: rapidez, empregabilidade, conhecimento. Para o concludente, novamente a ordem foi modificada e novamente o conhecimento passa a ocupar a segunda colocação: rapidez, conhecimento, empregabilidade.

A expectativa do aluno em relação ao curso seqüencial também foi questionada e novamente houve uma alteração significativa em relação à ordem de evocação de palavras. O ingressante indica, por ordem prioritária de escolha, as seguintes palavras/expressões: empregabilidade, conhecimento, reconhecimento social. No concluinte, observa-se nova seqüência: conhecimento, empregabilidade, reconhecimento social.

\section{Considerações Finais}

A modalidade de cursos superiores seqüenciais, apesar de recente vem gradativamente conquistando seu espaço no mercado de trabalho, mesmo ainda sofrendo pesadas criticas no meio acadêmico. Desconhecendo esse cenário as pessoas procuram os cursos seqüenciais a fim de atender a uma exigência do mercado de trabalho pela obtenção do diploma.

Ao ingressar em um curso seqüencial, confirmando a observação empírica, o aluno traz uma visão pragmática e procura prioritariamente rapidez, ou seja, um curso superior de curta duração para melhorar a sua empregabilidade a curto prazo.

Em sua grande maioria, as palavras evocadas tanto pelos ingressantes como pelos concluintes são as mesmas, conforme observado no quadro 2, supracitado. As principais evocações foram rapidez, empregabilidade, conhecimento, reconhecimento social, reconhecimento profissional, em diferentes classificações, dependendo da pergunta e da posição do aluno no curso. Essas modificações na posição das palavras evocadas indicam que as representações sociais dos discentes estão sofrendo alterações no decorrer da sua formação, possivelmente pela convivência com o ambiente acadêmico, tendo em vista que a maioria dos docentes, seguindo a política da instituição, são exigentes quanto ao rigor científico na elaboração de trabalhos e na qualidade do ensino.

É importante registrar que os alunos estão 
fazendo uma associação entre curso seqüencial e empregabilidade, palavra evocada em praticamente todas as questões do questionário apresentado. A aquisição de novos saberes vem sendo percebida, tanto pelos ingressantes, como pelos concluintes, como um fator imprescindível da empregabilidade.

Em relação ao objetivo proposto, pode-se concluir que está havendo uma re-significação das representações sociais dos discentes e que 0 pragmatismo inicial vem sendo modificado no decorrer do curso por um interesse mais acadêmico. O aluno ingressante no curso seqüencial pela rapidez em obter um diploma superior e atender a uma exigência de mercado, mas ao longo do curso, o fator empregabilidade cede posição para o conhecimento, que passa a ser priorizado. O curso seqüencial passa a ser percebido também como um passo para um maior aprofundamento nos estudos e a representação inicial transforma-se e transforma no aluno as representações sociais.

\section{Referências}

ALVES-MAZOTI, A. J; GEWANDSZNAJDER, F. O método nas Ciências Sociais: pesquisa quantitativa e qualitativa. São Paulo: Pioneira, 2001.

\section{BRASIL. Lei de Diretrizes e Bases da Educação} Nacional - LDB. Lei no 9.394/96, de 20 de dezembro de 1996.

\section{Lei de Diretrizes e Bases da}

Educação Nacional - LDB. Lei no 4024, de 20 de dezembro de 1961.

Decreto Lei $\mathbf{n}^{\circ} \mathbf{5 4 7}$, de 18 de abril de 1969. Publicado no Diário Oficial da União - DOU de 22 de abril de 1969.

Parecer CNE/CES n ${ }^{\circ} 436$, de 02 de abril de 2001. Publicado no Diário Oficial da União - DOU de 06 de abril de 2001.

Resolução Conselho Nacional de Educação - Câmara de Educação Superior (CES) $n^{\circ} 1$, de 27 de janeiro de 1999.

. Ministério da Educação/INEP. Censo do ensino superior, anos 1998, 1999, 2000, 2001, 2002, 2003. Disponível em www.inep.gov.br. Acesso em outubro de 2008a.

. Instituto Brasileiro de Geografia e Estatística - IBGE. Pesquisa Mensal de Emprego. Disponível em www.ibge.gov.br/home/estatistica/indicadores. Acesso em outubro de 2008b.

CAVEDON, N. R. Antropologia para administradores. Porto Alegre: Editora da UFRGS, 2003.

COSTA, S. G. da. Redução de postos de trabalho e empregabilidade: uma análise a partir de um programa de demissões voluntárias. In:

BITENCOURT, C. et al. Gestão contemporânea de pessoas: novas práticas, conceitos tradicionais. Porto Alegre: Bookman, 2004.

COTRIM, G. História e consciência do Brasil. 2. ed. São Paulo: Saraiva, 1995.

COUTINHO, M. da P. de L. Depressão infantil: uma leitura psicossociológica. In: MOREIRA, A.S. P.

(Org.). Representações sociais: teoria e prática. João Pessoa: Editora Universitária / Autores Associados, 2001.

DEMO, P. Participação é conquista. 3. ed. São Paulo: Cortez, 1996.

DURKHEIM, E. As formas elementares da vida religiosa. São Paulo: Abril Cultural, 1978.

FÁVERO, M. de L. Universidade \& poder. Rio de Janeiro: Achimé, 1980.

JOVCHELOVITCH, S. Vivendo a vida com os outros: intersubjetividade, espaço público e representações sociais. In: GUARESHI, P.; JOVCHELOVITCH, S. (Orgs.). Textos em representações sociais. 2. ed. Petrópolis: Vozes, 1995.

MANFREDI, S. M. Educação profissional no Brasil. São Paulo: Cortez, 2002.

MARTINS, R. de O. Cursos seqüenciais. Bauru: Edusc, 2004.

MASETTO, M. (Org.). Docência na universidade. 8. ed. Campinas: Papirus, 2006.

MINAYO, C. de S. Pesquisa social: teoria, método e criatividade. Petrópolis: Vozes, 2002.

MOSCOVICI, S. Prefácio. In: GUARESHI, P.; JOVCHELOVITCH, S. (Orgs.). Textos em representações sociais. 2. ed. Petrópolis: Vozes, 1995.

MOSCOVICl, S. Representações sociais: investigação em psicologia social. Petrópolis: Vozes, 2003.

OLIVEN, A. C. A marca de origem: comparando colleges norte-americanos e faculdades brasileiras. Cadernos de Pesquisa, v. 35, n. 125, maio/ago, . 111-135, 2005.

PEREIRA, E. M. de A. Estudo sobre cursos seqüências - resolução CES No 1/99 do CNE e deliberação No 7/99 do CEE, disponível em http://www.prg.unicamp.br/est._cursos_sequenciais _elisabete_monteiro.html. Acesso em junho 2007. 
SANTOS FILHO, J. C; GAMBOA, S. S. Pesquisa educacional: quantidade-qualidade. São Paulo: Cortez, 1995.

SAVIANI, J. R. Empresabilidade: como as empresas devem agir para manter em seus quadros elementos com alta taxa de empregabilidade. São Paulo: Makron Books, 1997.

SPINK, M. J. Desvendando as teorias implícitas: uma metodologia de análise das representações sociais. In: GUARESHI, P.; JOVCHELOVITCH, S. (Orgs.). Textos em representações sociais. 2. ed. Petrópolis: Vozes, 1995.

TEIXEIRA, A. O ensino superior no Brasil: análise e interpretação de sua evolução até 1960. Rio de Janeiro: Fundação Getúlio Vargas, 1989.

VERGARA, S. C. Métodos de pesquisa em administração. 2. ed. São Paulo: Atlas, 2006. 